\title{
The Dynamics of Design- Knowledge Construction: The Case of a Freshman Architectural-Design Studio in Egypt
}

\author{
Nouran Mohammed Haridy* \\ Arab Academy for Science, Technology and Maritime Transport, Cairo, Egypt \\ and Egyptian Russian University, Cairo, Egypt \\ Marwa Hassan Khalil ${ }^{(D)}$ and Ramy Bakir \\ Arab Academy for Science, Technology and Maritime Transport, Cairo, Egypt
}

\begin{abstract}
Reviewing the literature indicates a lack of studies that explicitly describe the dynamics of design-knowledge construction in architectural pedagogy. Accordingly, this study attempts to empirically explore the process of constructing design-knowledge within a freshman architectural-design studio in the Egyptian context. In the spring 2020 semester, interpretive qualitative research was initially conducted in an on-campus setting, followed by a period within an online setting, after the COVID-19 lockdown. A total of 12 students, in addition to four teaching assistants and the course instructor, were involved in this study. Multiple data-gathering tactics, such as field observations, semistructured interviews, and document archives were employed. Conventional content analysis was adopted, in order to extract the patterns that describe the design-knowledge construction within the case under investigation. The study revealed ten themes within three categories: students' learning activities, faculty-pedagogical strategies, and social interactions. This paper discusses one theme from each of these categories: (1) students' recourse to self-directed learning, (2) the faculty's coaching within the educational setting, and (3) the studio's sociocommunal cohesion. The findings of this study confirmed that the construction of design-knowledge is an integrally situated process, which cannot be studied without the presence of all its various components. Such a study presents a contribution that could inform future pedagogical initiatives which aim to create stimulating architectural learning environments in a post-pandemic reality.
\end{abstract}

Keywords: Design education; architectural design studio; freshman students; situated learning perspective; design-knowledge construction

\footnotetext{
*Corresponding author: Nouran Mohammed Haridy, Nouran.Har-idy@student.aast.edu
} 


\section{Introduction}

Knowledge is viewed as a collage of experiences that are "distributed among people and their environments, including objects, artifacts, tools, books, and the communities of which they are a part" (Greeno et al., 1996, p. 17). This knowledge is constructed when participants actively interact and build an understanding of concepts, phenomena, and situations (Chang, 2018; Lave \& Wenger, 1991; van Aalst, 2009). In the field of design, the construction of design- knowledge has been a key process in the architectural learning environment (Cross, 2006; Lueth, 2008; Schön, 1988). Consequently, one must understand how design-knowledge can be constructed, in order to inform the teaching and learning experiences.

Previous studies within the architectural-learning environment addressed the basis of design-knowledge by identifying its typology (Bashier, 2017; Schön, 1988; Khan \& Thilagam, 2021), its potential sources (Lawson, 2001; Tzamir \& Churchman, 1989), and the different ways of knowing this in the studio (Heylighen et al., 1999). However, the present study goes deeply to explore the dynamics of design-knowledge construction within contemporary architectural pedagogy, specifically in the era of COVID-19, where online and hybrid learning are no more optional, but rather a necessity. Moreover, this study considers the subjective property of design-knowledge as being invisible (Lawson, 2004), and it is asituated property; since it cannot be separated from its context (Bucciarelli, 2001; Sopher, 2019). Therefore, an empirical exploration was adopted, in order to better understand this phenomenon in its context.

Our approach parallels those empirical studies that investigated ways whereby design-knowledge is constructed, either through examining a particular teaching pedagogical model in relation to knowledge construction (Cennamo \& Brandt, 2012; Kamble, 2016; Uluoğlu, 2000), or by studying the benefits of utilizing a supporting educational tool in the design studio (van Kampen, 2019; Sopher et al., 2019). However, our work focuses holistically on investigating the process of constructing design-knowledge in a specific environment, in which learning is embedded within various activities, social practices, and within the learning context itself.

Students, in their first-year experience, have the challenge of adapting to a new learning environment (Picton et al., 2018) that will shape their attitudes and performance in their subsequent years. Accordingly, this study focuses on freshman-design studios, in order to better understand those earlier studies, which should provide valuable insights and approaches to architectural pedagogy.

In that sense, an interpretive qualitative study was conducted, in order to explore the dynamics of design-knowledge construction by portraying students' day-today activities. The study aims to present a holistic picture of the practices that take place within a freshman-architectural design studio in the Egyptian context. This is achieved by investigating the teaching and learning activities that occur throughout the learning process, in addition to the social interactions that 
emerged between the involved participants, along with an identification of the media that were utilized in the teaching and learning processes.

\section{The theoretical framework}

\subsection{Learning Theories and the Phenomenon of Knowledge Construction}

Since learning is considered as a process of constructing knowledge, various learning theories have attempted to undertake an analytical perspective on it, with respect to the building of a learner's knowledge. Cognitive constructivism views learning as the process of actively constructing knowledge by individuals (Piaget, 1971). This is followed by the social constructivists, who expanded the learning process to include the social construction of knowledge with other participants (Vygotsky, 1978).

Constructionism assumes that knowledge is constructed when the learner is engaged with the externalization and sharing of a mediated artifact (Papert, 1991). Furthermore, social constructionists added that after the externalization, students internalize the received feedback from other participants, and they then externalize it again, by remaking new ideas. However, situated cognition views learning from a different perspective that criticizes the decontextualization of knowledge from its situation. It argues that learning is all about the particular situations, in which knowledge has been learned and constructed, namely, the Authentic Context (Brown et al., 1989).

Legitimate peripheral participation, as developed by Lave and Wenger, situated learning in its environment; since "learning is an integral part of generative social practice in the lived-in world" (Lave \& Wenger, 1991, p. 35). They proposed that learning is the process of participation in the communities of practice, in which knowledge is constructed dynamically. The key components of such an environment are the community activities, the systems of relationship in the community, and the authentic context in which this practice is embedded.

\subsection{Knowledge Construction through the Lens of the Situated Perspective}

The topic of knowledge construction has been broadly reviewed theoretically and explored empirically from varying perspectives among different educational disciplines (Chang, 2017; Koh et al., 2010). Louis L. Bucciarelli (2001) in his examination of engineering students, found that knowledge is very much contextdependent, socially constructed; and it relies on individual contributions. This explains the situated nature of knowledge construction and the relevance of a situated perspective in this field.

In order to be able to study the knowledge construction from a situated perspective, Johri et al. (2014) discussed the three analytical aspects of the situated learning of engineering students. These aspects are the primacy of action and interaction, participation and identity, and the mediation in social and material contexts. Likewise, Venkatesh and Ma (2021) proposed a conceptual framework for tacit knowledge construction in design education that relies on a pedagogical approach and individual construction, in addition to the social construct shaped through contexts, collaborations, and interactions in the design studio. 
In the same manner, Hadas Sopher (2019) in her PhD dissertation, as well as from other publications (Sopher et al., 2019), proposed a situated analytical model in the architectural learning environment that is based on the notion of place, referring to it as the Knowledge-Construction Activities model. This model presented a detailed description of each learner's design decisions related to the design activity occurring, along with the social and spatial settings. Her dissertation illustrated that the architectural-design studio provides an apt example of a situated-learning environment (Sopher, 2019).

Based on previous accounts, which discussed the situated nature of the architectural learning environment, the following sections present a detailed description of the key components of constructing design-knowledge that were employed to analyze the case under study. These components are: (a) activity, (b) social engagement, and (c) authentic context.

\section{(a) Activity}

The work of Donald Schön (1988) and others (Jolley, 2013; Oluwatayo et al., 2017) illustrated that the design activities practised by the students play a significant role in constructing design-knowledge through interacting with an ill-defined problem, in order to ultimately develop it into a final design artifact. Furthermore, several studies highlighted the various challenging roles that tutors have to adopt in co-constructing design-knowledge (Goldschmidt et al., 2010) via different approaches and methodologies in teaching architectural students (Cennamo \& Brandt, 2012; Kamble, 2016).

The identified significant role of those learning and teaching activities is consistent with Lave and Wenger's work, in which they established the idea that the focal process of learning is grounded in the activity in which the community functions (Lave \& Wenger, 1991). Accordingly, this study has been quite attentive to students' activities occurring throughout the learning process and the faculty's pedagogical strategies that were applied within the educational setting, as parts of the learning and the teaching activities.

\section{(b) Social Engagement}

The architectural learning environment has the necessary conditions to establish what Lave and Wenger referred to as the significant systems of relationship in the community (Sopher, 2019). Social engagement in the design studio can be seen in the rich processes of social interactions between faculty members, the design student, and the student's peers (McClean \& Hourigan, 2013; Schön, 1988). Such interactions play a part in mediating and disseminating appropriate practices and values in design education (Ashton \& Durling, 2000; Türkkan et al., 2013). Even in the online setting, where there is a lack of face-to-face interaction, Lotz et al. (2015) observed a high level of engagement and social interactions among students. Accordingly, this study focuses on investigating these social interactions that emerged between the involved participants. 


\section{(c) Authentic Context}

The design studio, as a physical educational setting, was initially seen as the context for design instruction. It was viewed as "the kiln where future architects are molded. It is the primary space where budding professionals explore their creative skills, which are so prized by the profession" (Salama, 2009, p. 19). As the delivery of design education has moved into online settings, scholars have begun to recognize that exploring these learning settings may be of greater importance than previously acknowledged (Al-Qawasmi, 2007).

Specifically, after the break of the COVID-19 pandemic, several attempts were noticed to study the dynamics of those online settings; since the educational institutions have been totally dependent on them (Al Maani et al., 2021; Bakir et al., 2021; Khan \& Thilagam, 2021). However, this study does not view the delivery of design education, as being based only on the educational settings, physical or online; since it is rather based on the interaction with those media through which learning can be derived.

These media are the ways in which learning and teaching activities are facilitated through resources, utilized tools, representational modes, and communication networks. Previous researchers in architectural education have found that the knowledge-construction can be enhanced by engaging students with diverse learning media, such as precedents and physical models (Kamble, 2016). In addition, online communication channels play a significant role in promoting a continuous dialogue between faculty members and students, and/or students with each other (Lotz et al., 2015; Venkatesh \& Ma, 2019).

Within Egyptian architectural studios, Bakir and Alsaadani (2019) found that social media, and particularly Facebook groups, support design pedagogy in general, and specifically the students, by providing them with knowledge, guidance, interaction, and archiving tools.

Regarding the role of such media, this is consistent with what Lave and Wenger (1991) highlighted regarding the role of engagement with the artifacts of practice. They noted that the role is not merely learning to use tools; rather, it is in mitigating the challenge of access to the new community, and then becoming a full participant. Consequently, this paper will seek to present a better understanding of how the media were used, while identifying their significance in the construction of design-knowledge.

\section{The Method}

As the study attempted to empirically explore the dynamics of design-knowledge construction within an architectural learning environment, interpretive qualitative research was adopted to investigate the phenomenon in its natural setting. This type of research gives a holistic picture of the phenomenon under investigation in its natural setting, by gathering detailed information gleaned from the involved participants (Denzin \& Lincoln, 2013; Yin, 2018). Such an interpretive approach allows researchers to understand the interactions at a certain point of time, within a particular context, from the stakeholders' 
perspective (Merriam \& Grenier, 2019); which thereby renders it relevant to the study's objective.

\subsection{The Context of the Study}

The present empirical work was conducted in the Department of Architectural Engineering and Environmental Design at the Arab Academy for Science, Technology and Maritime Transport (AASTMT), on the Cairo campus, Egypt. The AASTMT educational setting was selected; since the first author is enrolled there as a postgraduate student, which allowed access to data, resources, and other participants. The 'AR211: Architectural Design I' course, which takes place in the second year of the five-year undergraduate architecture program at AASTMT, was selected as the case under study, being the first design studio in the program.

The selection of this course was also because it has been implemented as a'Projectbased' model as a teaching method since the spring 2007 semester. It was believed that this model would add more richness to the study's findings; since it guides freshman students to engage in meaningful interactions.

As an introductory design studio AR211 employs two design projects across the academic semester. The first design project usually tackles a residential prototype, in which students are required to do specific tasks every week, aiming to build students' knowledge pertaining to the principles of architectural design through gradual and cumulative learning. While in the second project, students are encouraged to go through a systematic design process that should help them in their subsequent design projects.

\subsection{The Phases of the Study}

The present empirical study proceeded in two phases: a pilot study, followed by the main study. The pilot study was conducted in the fall 2018 semester for the AR211 course. It helped in becoming familiar with the course, its content and phases, and in refining and shaping the inquiry method to be used in the main study.

The academic semester spring 2020, in which the main study was conducted, was planned to last for 16 weeks on campus. However, the academic plans were changed in March 2020, in order to cope with the unexpected COVID-19 lockdown that occurred at the start of the sixth week, when the World Health Organization (WHO) announced Covid-19 as a pandemic (World Health Organization, 2020). This has resulted in switching the rest of the semester to be taught virtually. Therefore, the actual course duration was extended to be 17 weeks in total, eight weeks of which were for a seaside residence project and nine weeks were for a celebrity's house project (Figure 1). The scheduled contact hours per week were eight hours on average, conducted on Sundays and Wednesdays. 


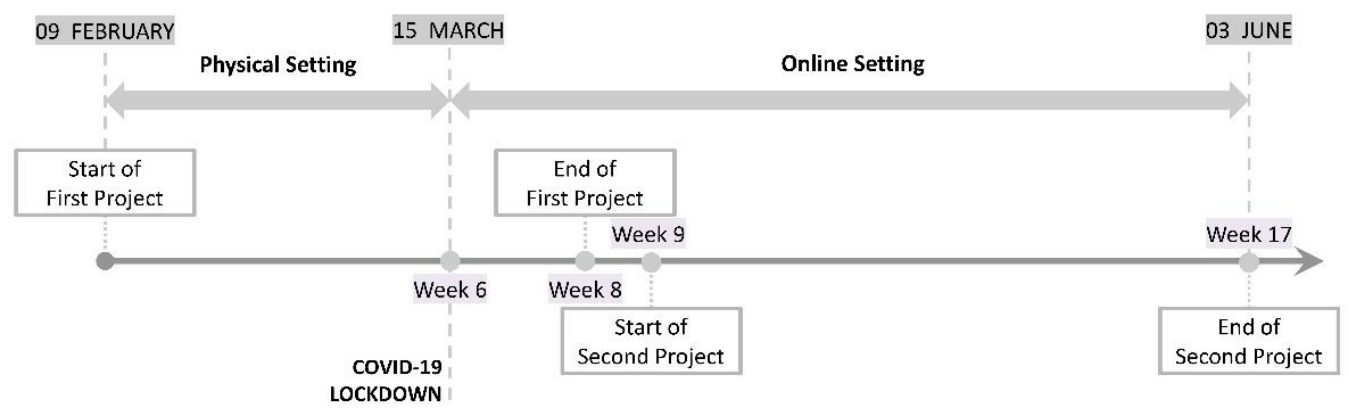

Figure 1. Overview diagram for the spring 2020 semester

\subsection{The Involved Participants}

The whole cohort that registered for the AR211 course in the spring 2020 semester was divided into three studios, with different instructors and teaching assistants (TAs). 45 students were enrolled in the selected studio under the supervision of one course instructor and five Teaching Assistants. Each TA was to be supervising a small group, from eight to ten students. The involved participants in this study comprised 12 students, six males and six females $(26.6 \%$ of the studio's total population), the course instructor, and four TAs. The selection of the involved participants was based on those who agreed to participate in the study.

During the first five weeks of the semester, five students, along with their four TAs and the course instructor, were involved in the study. After the COVID-19 lockdown, one group composed of nine students and led by a TA, volunteered to participate in the rest of the study. In addition, the course instructor and another two TAs participated in a few sets of the online meetings. Two students with their TA were constantly traced across the whole semester, as highlighted in Figure 2.

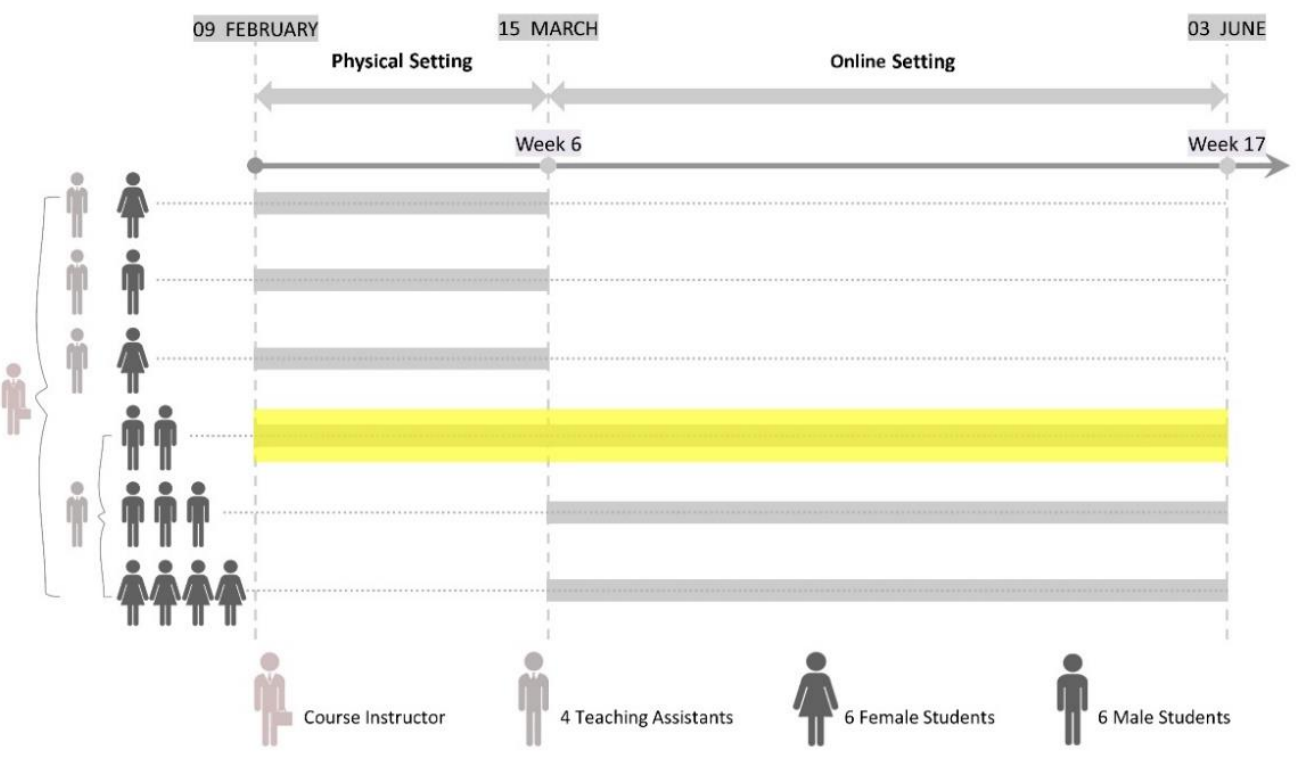

Figure 2. Distribution of the involved participants across the whole spring 2020 semester 


\subsection{The Data Collection}

Based on the previous contextualized studies (Cennamo \& Brandt, 2012; Sopher, 2019), this study employs multiple data-gathering methods. Such methods include field observations, semi-structured interviews, and document archivals, in order to holistically interpret what the participants are doing. The use of such multiple techniques enhances the internal validity of the findings (Merriam \& Grenier, 2019; Yin, 2018). Furthermore, Bryan Lawson noted that "No one technique, and indeed no one piece of research, can give us all the answers. Somehow, we have to take it all together, with all the caveats and cautions that are appropriate, in order to obtain an overall picture" (Lawson, 2004, p. 5).

Field observation was conducted for portraying the actual live set-up, in order to describe comprehensively the learning activities across the whole semester. This was documented in the form of:

- The researcher's field notes during lectures and studio sessions,

- The photographs and screenshots that captured different learning events and students' work, including sketches, physical models, and follow-up drawings, etc.,

- 30 hours of extensive video captured for most of the interactions among the involved students and faculty members in physical and online settings, as well as

- Six hours of audio recordings for selective situations in the physical setting, including lecture durations and collective-design discussions.

The interviews were conducted for triangulating the findings, in order to provide insight into the inputs that assisted students in their design developments - from their own point of view. 21 interviews were conducted with the five involved students in the physical setting only; since it was difficult to approach all the students on a regular basis in the online setting. Semi-structured interviews were chosen; since this permits the interviewer to enjoy greater flexibility for expanding and clarifying the informants' responses, in addition to raising other questions that might occur (Yin, 2018).

The interview contained open-ended questions, aiming to capture what students had developed in the on-going stage of the design project, followed by more indepth questions about the specific issues related to the participants' comments. The interview duration varied, according to each student's amount of progress. A total of six hours and 27 minutes were documented for the interviews, either in the form of videos, or audio recordings.

In addition to these techniques, several documents were collected, including course formal documents, such as project headers and assessment sheets, and the project submissions, such as the final submissions. These documents, along with the documentation of observations and interviews, were all used to support our interpretations of the phenomenon under investigation. 


\subsection{The Data-Analytical Procedures}

The collected data were converted into a format that facilitates analysis by transcribing the audio and video recordings for design discussions and interviews, and then inserting the transcripts into a database table by Microsoft Office Excel sheets. The transcripts were divided into smaller units, each unit was grouped textually under a common idea. Additional data were included also, such as the date, the recording method, and the duration of the session, along with attached photos related to the on-going discussion. Conventional content analysis was adopted; since it searches for any preconceived patterns not gleaned from the participants' words (Hsieh \& Shannon, 2005).

Initial codes were assigned to the meaning units by the first author, with the aid of the co-authors, thereby aiming to reach consensus (Graneheim et al., 2017). The coding process went through cyclic iteration and refinement, in order to depict an accurate picture of the design-knowledge construction. To check the reliability of the assigned codes, the units that were assigned for the same code were compared to each other, in order to refine the dimensions of the existing codes, and to identify any new codes.

\section{The Findings and Discussion}

The study extracted ten themes, of which four themes related to students' learning activities, four themes related to faculty pedagogical strategies, and two themes related to participants' social interactions. Due to the limitation of word counts, one theme for each of these categories, as highlighted in Figure 3, will be further discussed in the following sub-sections. Direct quotes from the recorded discussions and the interviewees' responses will be used to support the findings, along with an example of the students' work samples.

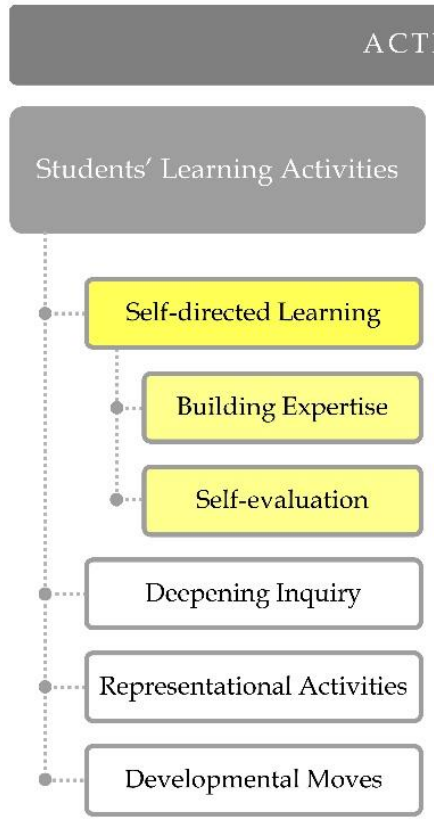

\section{ACTIVITY}

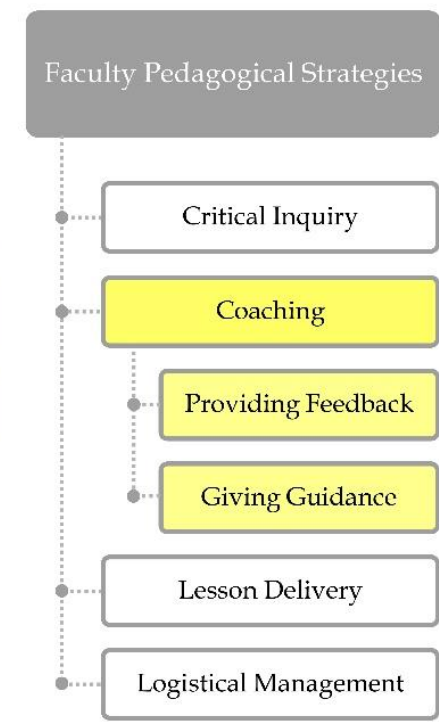

\section{SOCIAL ENGAGEMENT}

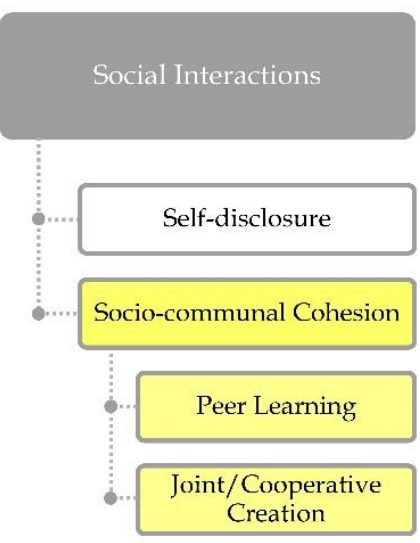

Figure 3. Extracted themes from among activity and social engagement 


\subsection{The students' various learning activities}

The analysis of the students' learning activities revealed only the overt (observable or mentioned) activities. Four themes were extracted, as shown in Figure 3, first column. It was noted that the students were usually involved with a process of self-directed learning that comprises a set of activities carried out at the individual level, in order to confirm learning by actually implementing it. In addition, further processes for deepening inquiry were deduced, in which students look for more investigations, in order to reach conclusions or ideas. This was followed by diverse representational activities applied to express the students' outcomes.

Consequently, the students were able to make developmental moves, in order to achieve their final product. The following section will further discuss the students' recourse to self-directed learning.

Self-directed learning was based on the individuals' investments. This correlates with Brookfield's definition of self-directed learning, as a process "in which the conceptualization, design, conduct and evaluation of a learning project are directed by the learner himself" (Brookfield, 2009, p. 2615). In that manner, two sub-themes were captured on how that was demonstrated: building expertise and self-evaluation.

The identified patterns of building expertise revealed that the use of self-directed activities could enrich students' collage of knowledge, so that they would be able to design. Various resources were approached in those patterns, such as reference books, work samples of others, videos, internet-search engines, and specialized websites. It was deduced that these resources positively assisted the applicability of those patterns, by providing a platform for diverse available information.

We have noticed that most of the students tended to build their body of information through reading about a subject matter, searching for deep information, and looking at precedents. For the reading purpose, student N.S. said that "Considering this painting, I read about it and why the painter did it in this way" during the design discussions. Additionally, student M.O. was searching for more information about a particular celebrity, by viewing a video-taped interview with him. In addition, it was observed that some of the students were bringing pictures for precedents, in order to discuss them with their faculty members.

Also, a number of students applied more unconventional approaches. They used to follow public figures' official accounts among social-networking platforms, such as Facebook, Instagram, and YouTube. It was found that tracking a celebrity's account can provide several pieces of information, like celebrity biography and samples of his/her on-going professional work. That was noticed when a TA asked one of the students if he had read that this celebrity was working in politics, literature, and photography, or not; and the student M.G. confirmed that by saying: "That was written in his biography on his own Facebook account." 
Complementing the previous patterns of building expertise, students used to undertake trials, through which they learnt by replicating the process of designing until reaching the sufficient product. Several alternatives had been observed for the design of different architectural projects, as shown in Figure 4. Furthermore, the simulations of the final board design had been developed through cutting the different architectural projects, and trying to assemble them on the drawing board, either manually or digitally.

Here, computer software, as a utilized tool, played an important role in facilitating this process of simulation.
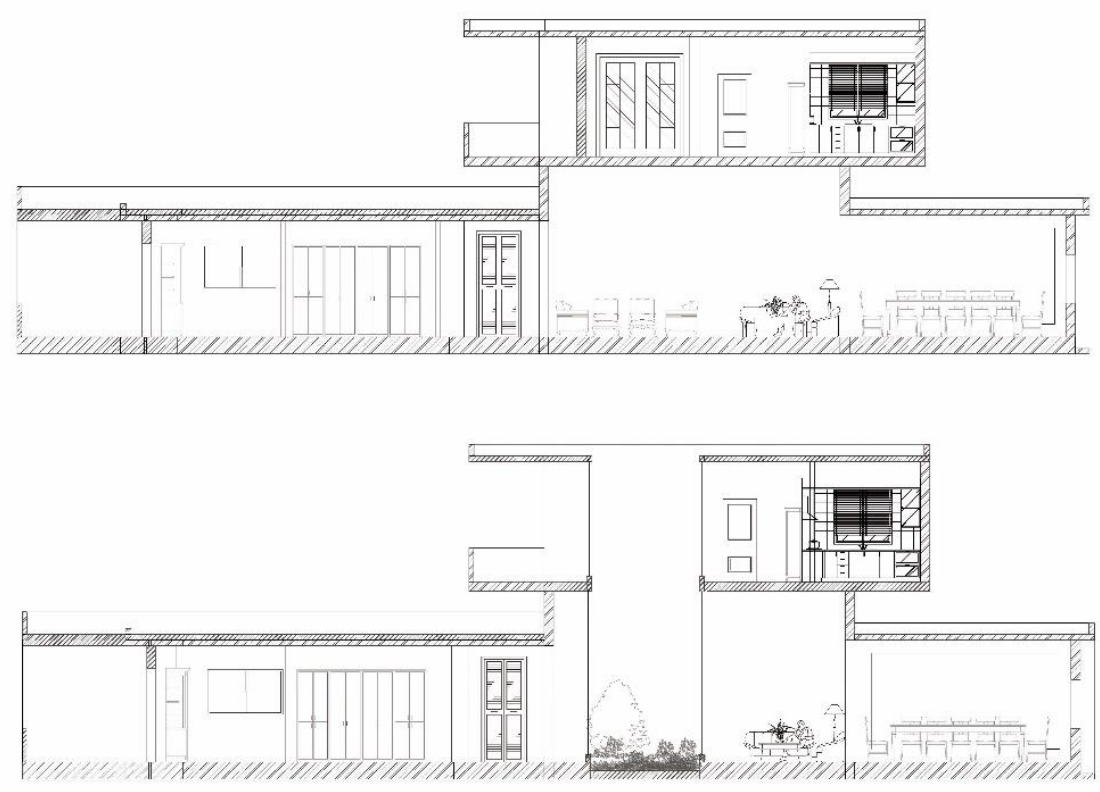

Figure 4. Screenshots of student M.G.'s trials for the section design

As for self-evaluation, it was deduced that most of the students used to assess their own positions, in order to build a strategy for the future developmental move. We have noticed that highlighting the strength and identifying the weakness, were found in both the direct quotes from the recorded discussions, as well as the interviewees' responses. During an interview session, student M.S. mentioned that she had decided to change the bedrooms' orientation to be North and East; and she was grateful for the success of this potential decision. Then she added, "However, the idea is that the lobby got a little bigger than I had expected." Here, another design issue was recognized and identified by the student, which in turn, needed to be revised.

Another pattern of self-evaluation activities was testing an idea, or the produced artifact, in order to make a design decision. Students commonly mentioned the "if I do so..., that...will happen," an assumed scenario to test the applicability of the presented solution, and subsequently a revision of the wrong assumptions. The importance of students' careful investigation was highlighted by Khalil (2021), as it could enhance the architectural design students' creativity levels and selfconfidence during the problem-solving process. 
Revising mistakes was another pattern of self-evaluation, which complements the previously mentioned patterns. This pattern emerged when students faced surprises during their elaborations, which could make them change their decisions, or reconsider their conclusions. For example, student N.D. confessed that the corridor was too long; and he was able to adjust that by placing a storage cabinet at its end, in order to reduce the corridor's length. He voiced that by saying, "I have to say that this was a part of the corridor too, but I recognized that and placed a storage cabinet there instead." At other times, students revised their mistakes from their conclusion, after a discussion with a faculty member, as voiced by the student A.A. to a faculty member "Yes. It does not have to be thirty; it has to be fifteen. I messed it up."

Based on the findings, it may be inferred that adopting a self-directed learning approach helped students in actively constructing their design knowledge. That can be done by internalizing new information through reading, searching for, looking at precedents, following public figures' accounts, and undertaking trials. This is consistent with what Atman and Bursic (1996) found that a minimal intervention, such as reading a textbook, made engineering-design students more sophisticated in their problem-solving strategies than those who had not. Also, the construction of knowledge could be done by confirming/excluding information by identifying the strengths and weaknesses, by testing an idea, or the produced artifact, and correspondingly revising any mistakes.

These emerged patterns for building expertise and self-evaluation confirm what previous studies noted, that formal education is not the only way to develop design expertise; but additionally, the individuals' personal investments play a magnificent role (Oluwatayo et al., 2017). Consequently, students have to be very attentive to their personal investments.

\subsection{Faculty Pedagogical Strategies}

Four themes were revealed in the analysis of the faculty pedagogical strategies, as shown in Figure 3, second column. Critical inquiry contributed to engaging the students in the different forms of critical thinking about things. Complementary to this, coaching was directed; and it assisted the students to reach the appropriate orientation. Lesson delivery, in addition, helped in understanding how expertise can ground an idea. Furthermore, a set of logistical-management techniques was adopted to facilitate the set-up of a stimulating atmosphere for learning. This paper will further discuss the attempts to coach an architectural student.

It was found that faculty members, represented as course instructors and TAs, were coaching the students during the different design stages. Two strategies emerged here: providing feedback on students' specific design projects, and giving different types of guidance that could help students through their designing journey. There were no significant differences among the strategies that were applied within either of the learning environments, the physical setting, or the online one.

Providing feedback was the most applied strategy among most of the recorded discussions, in which faculty members were responsible for suggesting proposals 
for change or improvement. The tools utilized by the faculty members played a significant role in communication. In the physical setting, tools, such as tracing paper and markers, were commonly used (Figure 5, up); whereas other digital tools, such as annotation and navigation tools, were used in the online setting (Figure 5, down).

However, the digital tools gave more flexibility in doing multiple trials, rather than the capabilities of the traditional physical tools, as they afford the students the ability to draw and clear several times on the same architectural project.

Faculty members were usually used to rectify mistakes, to provide alternatives or possibilities, and to illustrate to-do or not-to-do steps, as the three general patterns of providing feedback. A number of the TAs added a complementary pattern of explaining more detailed follow-up related to the subject matter. For example, the course instructor was providing feedback to a student on the dimensions of a duct by saying, "You have to think about rectifying one side to be 60 centimeters, in order to provide a space for plumbing requirements, if they want to do any maintenance. But less than that would make it difficult to do."

Then, he proposed another possibility to achieve the optimal use of this duct by saying, "The other thing I want to mention is, if you have a duct, then you can think about opening the window within the duct, instead of distorting the façade."

During the desk crits, these patterns of providing feedback were employed, without any specific order, to develop students' design projects. Taking this benefit further, Cennamo and Brandt (2012) noted that the magnificent role of inprogress critique could be seen on three levels: the presenter, who helped to move his/her design forward, the studio peers, who contributed to other's thinking and might re-use it to inform their designs, and the instructor, who might refine the existing activities, or add other ones, based on the understanding provided by the students during the feedback session. 

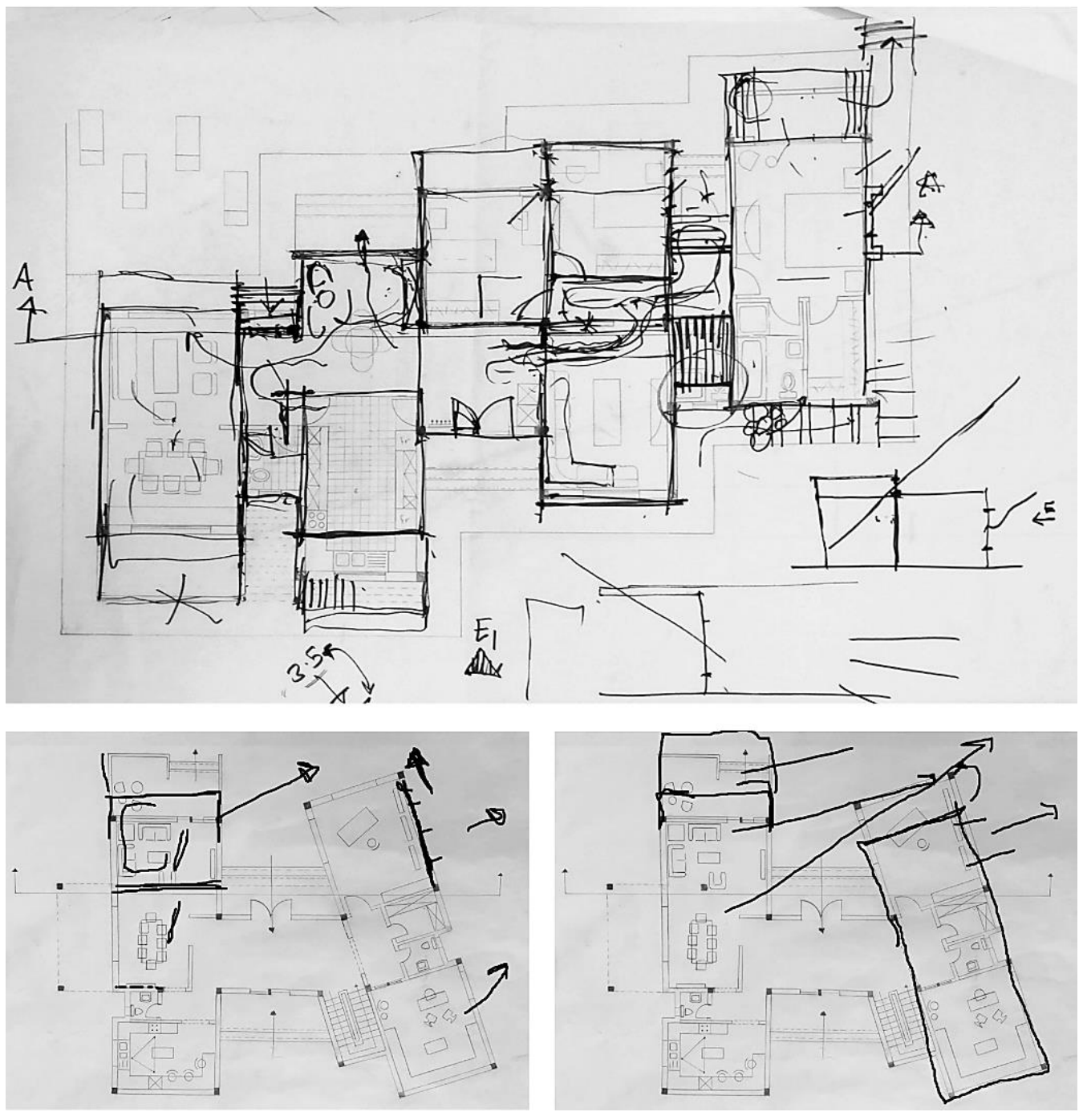

Figure 5. (Up) Photograph for TA A.S.'s feedback sketch, using physical tools in the studio. (Down) Screenshots for TA A.S.'s multiple trials, using digital tools in the online setting.

The second applied strategy for coaching was giving guidance, where faculty members were assisting, and adjusting learners' orientation during the designing journey. In most cases, faculty members were used to clarify strategy or know-how for a subject matter, which provides detailed steps for diverse learning operations. For example, TA A.S. mentioned the following steps to clarify the best strategy for extracting a grid or a module, on which to work. He said, "Write all the spaces that you will put inside the plan; and write the rough dimensions for each space." Moreover, he added, "Where will I get this information from? I will get it from Neufert. Then, I will decide which one of them might be common across all the spaces; and I can sub-divide it into small spaces, when I need to do so."

Clarifying the assessment criteria was another pattern of guidance that was adopted by some faculty members. They mentioned the assessment criteria for their evaluation, either at the beginning, or during the discussions. Furthermore, it was observed that students were told to be aware of the provided criteria for the 
design project. This way of explicitly providing the evaluation criteria was suggested by previous accounts, in order to mitigate the mystery component (Ragheb, 2016).

Another pattern of guidance was noticed during the tutoring sessions that some of the TAs used to give the students a focused additional activity or task, which offered opportunities for the students to work more on expressing ideas via visual representations. It also maximized the critical discussions of various products done by other studio peers. One of those activities was to furnish a master bedroom in seven different arrangements, using one bed, one closet, and two side tables. Student N.D. mentioned the positive influence of such an assignment by saying, "This assignment is a tricky assignment. It will not be solved directly; but it informs us on how to furnish any room quickly, without any wastage of space."

In that manner, Cennamo and Brandt (2012) illustrated the significant role of focused assignments, rather than the systematic assignment of designing a product of a students' choice, by providing more opportunities to listen-in to each other's conversations by conducting meta-discussions.

In that sense, providing feedback through rectifying mistakes, providing alternatives or possibilities, illustrating to-do or not-to-do steps, and adding detailed follow-up suggestions could develop the students' position. While, assisting the students' orientation could be done by clarifying the strategy, or know-how, clarifying the assessment criteria, and suggesting a focused activity.

These three strategies of coaching, providing feedback and giving guidance, appear to have together allowed the students to take a further step within the design processes. That confirms what Uluoğlu (1996) noted, that this kind of knowledge is about 'how-to-do' knowledge, and its means of explaining to students are by demonstrating, by showing solutions, and coaching, and by suggesting various strategies. Similarly, Venkatesh and Ha's model for tacit-knowledge construction (2021) confirmed that such pedagogical strategies can actually facilitate autonomous learning.

\subsection{Social Interactions}

Two themes were identified for the social interactions among the involved participants, as shown in Figure 3, in the third column. They include selfdisclosure, where a platform is opened, to reveal information about oneself to others, in addition to studio socio-communal cohesion, in which a sense of group commitment is built by interacting with others. The following section will focus on the studio socio-communal cohesion. Two sub-themes of studio sociocommunal cohesion were revealed, in which the involved participants interact effectively in co-constructing design knowledge, such as peer learning and joint/cooperative creation.

The most emerged patterns of peer learning were when students were encouraged by faculty members to comment, view, and provide alternatives or possibilities on other peers' ideas. During such a group crit, one of the students was presenting his choice for keywords that characterized a particular celebrity. In turn, student A.A. 
commented on this choice by saying, "I believe that he can find more keywords about this celebrity. I think the selected keywords are not strong enough." Furthermore, student F.N. showed his agreement by saying, "I agree with others' opinions that the selected keywords are generic. It is possible that many people would like to draw things. Furthermore, many people are working in landscape architecture, as it is. There is nothing specific about this celebrity." Moreover, a previous study found that these social-design skills are inherent aspects of creativity, which permit students to become active and reflective learners, by engaging in more negotiating activities (Türkkan et al., 2013).

Another interesting pattern of peer learning was mentioned by some students, when some of them used to consult each other outside the design-studio times. During the interview session, student M.G. noted that "someone called me to ask how to draw the hammerhead parking, and I helped him." Also, student M.S. noted that she was stuck in her design project, and she asked for help from her peer, who gave her valuable ideas for development. Ferreira (2018) noted this pattern, when he claimed that design students can learn from each other, but to a lesser degree than the one established with the instructor. Even in the e-learning platforms, Lotz et al. (2015) found a correlation between the engagement with other learners and the students' success; since these platforms allowed students to share and discuss their design works, asynchronously, with their peers at a distance.

Joint/Co-operative Creation was the second facet of studio socio-communal cohesion, in which the participants were continuing a theme, while discussing a subject matter. That kind of pattern enabled the co-construction of design knowledge. They were verbally complementing each other's sentences, during the selfexplanation, or when proposing a solution, rather than waiting for the partner to finish his/her thoughts and ideas (Figure 6, former rows). This is consistent with what Heylighen et al. (1999) mentioned regarding how dialoguing between students and the studio teacher is a way for opening up space for new meanings to be created. Furthermore, it was observed that sometimes the dialoguing was among faculty members, thereby enabling more clarification and generation of additional ideas (Figure 6, latter rows).

In the online setting, the use of different online networking platforms, such as Zoom, Google Hangout, and Moodle, helped in affording an alternative context to the face-to-face one, in which these kinds of dialogues can occur. This positive impact of online platforms was mentioned by Bakir et al., (2021), thereby highlighting the qualities that these platforms can provide to the educational context.

In addition to the verbal complementation, sketching and annotating on each other's drawings were other patterns of the joint/co-operative creation, in which the participants attempted to deliver their ideas. Interestingly, the different learning environments did not mitigate this kind of participation; since manual sketching was used in the physical setting, and digital annotation was used in the online meetings. That was explained by previous researchers, when they noted that 
teachers, as professional designers, need to describe the design imagery in their minds, and communicate it firstly with themselves, and then with others through several representations (Heylighen et al., 1999; Yazıc1 \& Doğan, 2019). Accordingly, such expression plays an important role for both the studio tutor as the sender, and with the student, as the receiver of directions.

\begin{tabular}{|c|c|}
\hline TA A.S.: & $\begin{array}{l}\text { Maybe if I do this and that, it could be a lobby or } \\
\text { not. }\end{array}$ \\
\hline Student M.G.: & $\begin{array}{l}\text { And here I can put a storage area and here also a } \\
\text { storage area. } \\
\text { (Complementing each other's proposed solution) }\end{array}$ \\
\hline TA A.S.: & Exactly \\
\hline TA A.S.: & $\begin{array}{l}\text { So, if I enter and try to grasp how the interior space } \\
\text { is looking like or the guests who are inside. }\end{array}$ \\
\hline Student M.G.: & $\begin{array}{l}\text { There are walls that will influence me to enter like } \\
\text { that. (Complementing each other's explanation) }\end{array}$ \\
\hline TA A.S.: & $\begin{array}{l}\text { Yes, I have to enter like that. And, I will not know } \\
\text { what is going inside. For example, maybe someone } \\
\text { is passing through the corridor and when I open the } \\
\text { door he will be seen if I was not putting those walls. }\end{array}$ \\
\hline $\begin{array}{l}\text { Course } \\
\text { instructor: }\end{array}$ & $\begin{array}{l}\text { If I looked at those three paintings, excluding the } \\
\text { fourth one, there are always two stories that can be } \\
\text { read from each one of them. Am I right? }\end{array}$ \\
\hline TA A.S.: & Okay. \\
\hline Student A.A.: & Yes. \\
\hline TA M.Y.: & Yes, right. \\
\hline $\begin{array}{l}\text { Course } \\
\text { instructor: }\end{array}$ & $\begin{array}{l}\text { So, we want to think about how to express those } \\
\text { two stories. }\end{array}$ \\
\hline TA M.Y.: & $\begin{array}{l}\text { This means that there is always a hidden meaning } \\
\text { within each painting. You can find that each } \\
\text { painting has a lot of small elements and the holistic } \\
\text { picture can give a meaning too. } \\
\text { (Complementing each other's explanation) }\end{array}$ \\
\hline TA M.Y.: & $\begin{array}{l}\text { In this painting, the small elements are the cheese } \\
\text { and the assembling of those parts gives you another } \\
\text { thing. While in this one, if you look at what it } \\
\text { contains, you will feel like it is a scenery } \\
\text { environment. But, if you look at the whole painting, } \\
\text { you will find a human face. }\end{array}$ \\
\hline Student A.A.: & $\begin{array}{l}\text { Exactly. He intended to do so. His paintings used to } \\
\text { be named something and he used to think about } \\
\text { another meaning. We are looking at it in different } \\
\text { ways. }\end{array}$ \\
\hline $\begin{array}{l}\text { Course } \\
\text { instructor: }\end{array}$ & $\begin{array}{l}\text { I like what you are saying. There are two things that } \\
\text { are common with each other and there are two } \\
\text { things that are completely different. }\end{array}$ \\
\hline TA A.S.: & $\begin{array}{l}\text { I think what the professor and teaching assistant is } \\
\text { saying, are more taking us towards polar or } \\
\text { duplexity. (Complementing each other's explanation) }\end{array}$ \\
\hline $\begin{array}{l}\text { Course } \\
\text { instructor: }\end{array}$ & $\begin{array}{l}\text { Duplexity is an excellent choice. It represents the } \\
\text { idea that each painting has two different meanings } \\
\text { at the same time. }\end{array}$ \\
\hline
\end{tabular}

Figure 6. Two segments from the recorded dialogues showing the verbal complementation among the involved participants. 
Based on the findings, contributing to peer learning, which represents the studentto-student interactions within and beyond the learning setting, can be done through commenting, viewing, providing alternatives or possibilities, and consulting each other. While to have joint/co-operative creations, students and faculty members need to appreciate the role of verbal and visualized dialoguing.

In that sense, we can mention that these kinds of student-to-student, student-tostudio tutor, and tutor-to-tutor interactions can assist in design knowledge coconstruction within both the physical and online learning settings.

All the aforementioned themes, sub-themes, and their relevant patterns are summarized in the figure below (Figure 7).

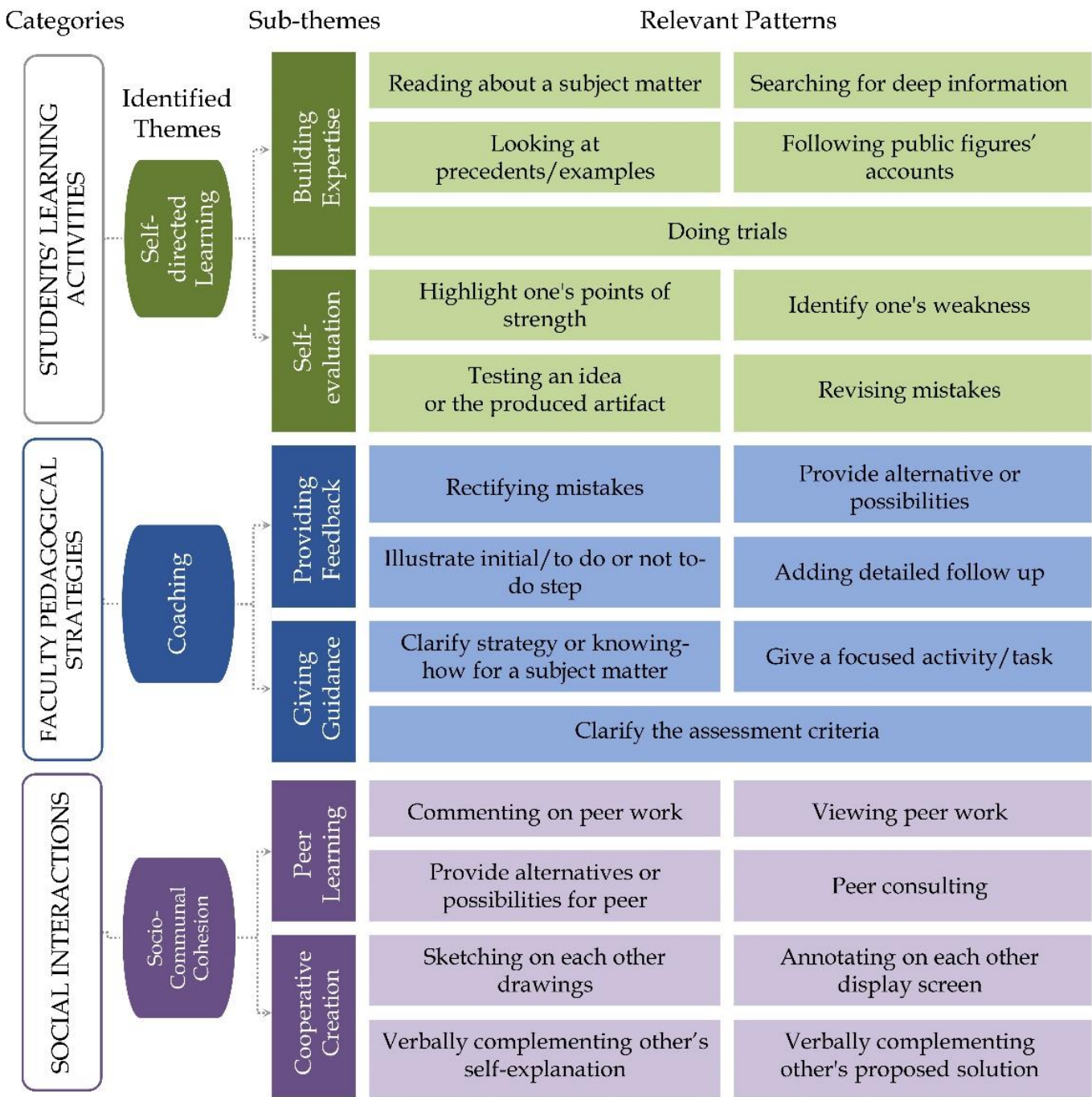

Figure 7. Hierarchical relation between the identified themes, sub-themes, and their relevant patterns 


\section{Conclusion}

The study has aimed to explore the dynamics of design-knowledge construction within a freshman-architectural design studio in the Egyptian context. The findings revealed ten themes that were found to inform the process of constructing design-knowledge. In this paper, we have discussed three examples of those extracted themes: self-directed learning related to the students' learning activities, coaching related to the faculty pedagogical strategies, and studio sociocommunal cohesion related to the participants' social interactions. The findings of this study confirmed that the construction of design-knowledge is an integrally situated process, which cannot be studied without the presence of all its various components. The role of students, as the initiators of the knowledge-construction process, has emerged in their various self-initiated activities. Students engaged with building expertise and self-evaluation, had the opportunity to generate more innovative ideas with the assistance of their attention to their personal investments in the learning process.

In addition, faculty members' coaching - rather than their teaching approach helped students in facilitating the knowledge construction by developing learners' positions, by assisting, and adjusting their orientations. Furthermore, peer learning and joint/co-operative creation have emphasized the importance of the participants' social interactions in design-knowledge co-construction.

As for the limitations of the study, the findings of this situated exploration cannot be generalized. Consequently, future research is encouraged to expand investigations to enrich the body of knowledge in the process of constructing design-knowledge in architectural pedagogy. Such research might help in providing a deeper understanding of the dynamics of design-knowledge construction in freshman architectural design studios, and in turn, thereby informing future pedagogical initiatives that aim to create stimulating architectural-learning environments.

Acknowledgements - The authors would like to thank all the involved students and faculty members for their time and willingness to participate in this study. They also extend their sincere acknowledgement to the College of Engineering and Technology at AASTMT - Cairo campus, for its support and encouragement.

\section{References}

Al Maani, D., Alnusairat, S., \& Al-Jokhadar, A. (2021). Transforming learning for architecture: Online design studio as the new norm for crises adaptation under COVID-19. Open House International, 46(3), 348-358. https://doi.org/10.1108/OHI-01-2021-0016

Al-Qawasmi, J. (2007). Virtualization of Architectural-Design Education in the Arab Region: Potential and Cultural Implications. Open House International, 32(2), 5564. https://doi.org/10.1108/OHI-02-2007-B0007

Ashton, P., \& Durling, D. (2000). Doing the Right Thing Social Processes in Design Learning. The Design Journal, 3(2), 3-14. https://doi.org/10.2752/146069200789390123

Atman, C., \& Bursic, K. (1996). Teaching engineering design: Can reading a textbook make a difference? Research in Engineering Design, 8(4), 240-250. https://doi.org/10.1007/BF01597230 
Bakir, R., \& Alsaadani, S. (2019). Facebook Posts and Design Pedagogy: An Egyptian Case Study of Social-Media Communication in Support of an Architectural Studio. In L. G. Chova, A. L. Martínez, \& I. C. Torres (Eds.), Proceedings of EDULEARN19, the 11th International Conference on Education and New Learning Technologies (pp. 98789887). IATED Academy. https://doi.org/10.21125/edulearn.2019.2460

Bakir, R., Alsaadani, S., \& Abdelmohsen, S. (2021). Student Experiences of Online Design Education Post COVID-19: Mixed-Methods Study. In S. Abdelmohsen, T. ElKhouly, Z. Mallasi, \& A. Bannadji (Eds.), Proceedings of the 9th Arab Society for Computer-Aided Architectural Design (ASCAAD) international conference 2021 (pp. 142-155). Robert Gordon University. http://ascaad.org/conference/2021/docs/proceedings.pdf

Bashier, F. (2017). Design Process-System and Methodology of Design Research. IOP Conference Series: Materials Science and Engineering, 245(8). https://doi.org/10.1088/1757-899X/245/8/082030

Brookfield, S. D. (2009). Self-Directed Learning. In R. Maclean \& D. Wilson (Eds.), International Handbook of Education for the Changing World of Work: Bridging Academic and Vocational Learning (pp. 2615-2627). Springer Netherlands. https://doi.org/10.1007/978-1-4020-5281-1_172

Brown, J. S., Collins, A., \& Duguid, P. (1989). Situated Cognition and the Culture of Learning. Educational Researcher, 18(1), 32-42. https://doi.org/10.3102/0013189X018001032

Bucciarelli, L. L. (2001). Design Knowing \& Learning: A Socially Mediated Activity. In C. M. Eastman, W. M. McCracken, \& W. C. Newstetter (Eds.), Design Knowing and Learning: Cognition in Design Education (pp. 297-314). Elsevier Science. https:// doi.org/10.1016/B978-008043868-9/50013-9

Cennamo, K., \& Brandt, C. (2012). The "right kind of telling": Knowledge building in the academic design studio. Educational Technology Research and Development, 60(5), 839-858. https://doi.org/10.1007/s11423-012-9254-5

Chang, B. (2017). Dialogues in Promoting Knowledge Construction. Adult Education Research Conference 2017, Norman, Oklahoma. https://newprairiepress.org/aerc/2017/papers/29/

Chang, B. (2018). Patterns of Knowledge Construction. Adult Education Quarterly, 68(2), 108-136. https://doi.org/10.1177/0741713617751174

Cross, N. (2006). Designerly Ways of Knowing. Springer. https:// doi.org/10.1007/1-84628301-9_1

Denzin, N. K., \& Lincoln, Y. (2013). The Discipline and Practice of Qualitative Research. In N. K. Denzin \& Y. Lincoln (Eds.), Collecting and Interpreting Qualitative Materials (4th ed.). SAGE Publications.

Ferreira, J. (2018). Design Conversations: An exploratory study of teacher and student interaction in the design studio [Doctor of Philosophy, Delft University of Technology]. https:// doi.org/10.4233/uuid:483619ed-6ddd-459b-bc21- 830424450f8d

Goldschmidt, G., Hochman, H., \& Dafni, I. (2010). The design studio "crit": Teacherstudent communication. Artificial Intelligence for Engineering Design, Analysis and Manufacturing, 24(3), 285-302. https://doi.org/10.1017/S089006041000020X

Graneheim, U. H., Lindgren, B.-M., \& Lundman, B. (2017). Methodological challenges in qualitative content analysis: A discussion paper. Nurse Education Today, 56, 29-34. https:// doi.org/10.1016/j.nedt.2017.06.002

Greeno, J. G., Collins, A. M., \& Resnick, L. (1996). Cognition and learning. In R. Calfree \& D. Berliner (Eds.), Handbook of Educational Psychology (pp. 15-46). Macmillan. https:// doi.org/10.4324/9780203053874

Heylighen, A., Bouwen, J. E., \& Neuckermans, H. (1999). Walking on a thin line - Between passive knowledge and active knowing of components and concepts in 
architectural design. Design Studies, 20(2), 211-235.

https:// doi.org/10.1016/S0142-694X(98)00035-0

Hsieh, H.-F., \& Shannon, S. E. (2005). Three approaches to qualitative content analysis. Qualitative Health Research, 15(9), 1277-1288.

https://doi.org/10.1177/1049732305276687

Johri, A., Olds, B., \& O'Connor, K. (2014). Situative frameworks for engineering learning research. In A. Johri \& B. Olds (Eds.), Cambridge Handbook of Engineering Education Research (pp. 47-66). Cambridge University Press. https://doi.org/10.1017/CBO9781139013451.006

Jolley, V. (2013). Constructing knowledge: A pedagogical evaluation of design-based learning. UCLan Journal of Pedagogic Research, 4. https://doi.org/10.5420/ujpr.4.

Kamble, T. (2016). Information Processing: Key to Knowledge Building in Architectural Design Studio. International Education and Research Journal, 2(12), 150-153. http://ierj.in/journal/index.php/ierj/article/view/619

Khalil, M. (2021). Idea Generating Techniques in Architectural Design Education: Exploring Students' Perceptions. International Journal of Engineering Education, 37(1), 65-85. https://www.ijee.ie/contents/c370121.html

Khan, A. R., \& Thilagam, N. L. (2021). The virtual design studio and the key integrals. Open House International, ahead-of-print(ahead-of-print). https://doi.org/10.1108/OHI-05-2021-0113

Koh, J. H. L., Herring, S. C., \& Hew, K. F. (2010). Project-based learning and student knowledge construction during asynchronous online discussion. The Internet and Higher Education, 13(4), 284-291. https:// doi.org/10.1016/j.iheduc.2010.09.003

Lave, J., \& Wenger, E. (1991). Situated Learning: Legitimate Peripheral Participation. Cambridge University Press. https://doi.org/10.1017/CBO9780511815355

Lawson, B. (2004). What designers know. Elsevier/Architectural Press.

Lawson, B. (2001). The context of mind. In P. Lloyd \& H. Christiaans (Eds.), Designing in Context: Proceedings of Design-Thinking Research Symposium 5 (pp. 133-148). Delft University Press.

Lotz, N., Jones, D., \& Holden, G. (2015). Social engagement in online design pedagogies. In R. Vande Zande, E. Bohemia, \& I. Digranes (Eds.), Proceedings of the 3rd International Conference for Design Education Researchers (pp. 1645-1668). Aalto University. http://oro.open.ac.uk/43592/

Lueth, P. (2008). The architectural design studio as a learning environment: A qualitative exploration of architecture design student learning experiences in design studios from first - through fourth-year [Doctor of Philosophy, Iowa State University]. https://doi.org/10.31274/rtd-180813-16991

McClean, D., \& Hourigan, N. (2013). Critical Dialogue in Architecture Studio: Peer Interaction and Feedback. Journal for Education in the Built Environment, 8(1), 3557. https://doi.org/10.11120/jebe.2013.00004

Merriam, S. B., \& Grenier, R. S. (2019). Qualitative Research in Practice: Examples for Discussion and Analysis (2nd ed.). Jossey-Bass.

Oluwatayo, A. A., Ezema, I., \& Opoko, A. (2017). Development of design expertise by architecture students. Journal of Learning Design, 10(2), 35-56. https://doi.org/10.5204/jld.v10i2.268

Papert, S. (1991). Situating Constructionism. In S. Papert \& I. Harel (Eds.), Constructionism: Research reports and essays 1985-1990. Ablex Publishing Corporation.

Piaget, J. (1971). The Theory of Stages in Cognitive Development. In D. Green, M. P. Ford, \& G. B. Flamer (Eds.), Measurement and Piaget (pp. 1-11). McGraw-Hill.

Picton, C., Kahu, E. R., \& Nelson, K. (2018). 'Hardworking, determined and happy': Firstyear students' understanding and experience of success. Higher Education Research E Development, 37(6), 1260-1273. https:// doi.org/10.1080/07294360.2018.1478803 
Ragheb, G. A. (2016). Assessment in Architectural Design Education Case Study: FirstYear Students at Pharos University. Journal of Civil Engineering and Architecture, 10(9), 1015-1026. https://doi.org/10.17265/1934-7359/2016.09.005

Salama, A. M. (2009). Transformative Pedagogy in Architecture and Urbanism. UMBAUVERLAG. https://doi.org/10.4324/9781003140047

Schön, D. A. (1988). Designing: Rules, types and worlds. Design Studies, 9(3), 181-190. https:// doi.org/10.1016/0142-694X(88)90047-6

Sopher, H. (2019). The notion of Place in design education. A situated learning model, using an immersive virtual environment [Doctor of Philosophy]. Senate of the Technikon Israel Institution of Technology.

Sopher, H., Gewirtzman, D. F., \& Kalay, Y. E. (2019). Going immersive in a community of learners? Assessment of design processes in a multi-setting architecture studio. British Journal of Educational Technology, 50(5), 2109-2128. https://doi.org/10.1111/bjet.12857

Türkkan, S., Sönmez, N., \& Kürtüncü, B. (2013). Neither Individual, nor Group: A First Year Design Studio Experiment. In M. Thorne \& X. Costa (Eds.), Proceedings of the 2012 ACSA International Conference (pp. 7-14). ACSA Press. https://www.acsaarch.org/chapter/neither-individual-nor-group-a-first-year-design-studioexperiment/

Tzamir, Y., \& Churchman, A. (1989). An Ethical Perspective on Knowledge in Architectural Education. Journal of Architectural and Planning Research, 6(3), 227239. https://www.jstor.org/stable/43028926

Uluoğlu, B. (2000). Design knowledge communicated in studio critiques. Design Studies, 21(1), 33-58. https://doi.org/10.1016/S0142-694X(99)00002-2

Uluoğlu, B. (1996). Representation of design Knowledge in Studio Critiques. In Ö. Akin \& G. Saglamer (Eds.), Descriptive Models of Design (pp. 577-591).

van Aalst, J. (2009). Distinguishing knowledge-sharing, knowledge-construction, and knowledge-creation discourses. International Journal of Computer-Supported Collaborative Learning, 4(3), 259-287. https://doi.org/10.1007/s11412-009-9069-5

van Kampen, S. (2019). An Investigation into Uncovering and Understanding Tacit Knowledge in a First-Year Design-Studio Environment. International Journal of Art E Design Education, 38(1), 34-46. https:// doi.org/10.1111/jade.12171

Venkatesh, A., \& Ma, C. F. H. (2021). Tacit Knowledge Construction in Studio-based Learning: A Conceptual Framework. The International Journal of Design Education, 16(1), 37-53. https://doi.org/10.18848/2325-128X/CGP/v16i01/37-53

Venkatesh, A., \& Ma, C. F. H. (2019). Tacit Learning in an Extended Interior Design Studio. In N. Börekçi, D. Koçyıldırım, F. Korkut, \& D. Jones (Eds.), Proceedings of DRS Learn X Design 2019: Insider Knowledge (pp. 237-245). Middle-East Technical University. https://doi.org/10.21606/learnxdesign.2019.01028

Vygotsky, L. S. (1978). Mind and society: The Development of Higher Mental Processes. Harvard University Press. https://doi.org/10.2307/j.ctvjf9vz4

World Health Organization. (2020, March 11). WHO Director-General's opening remarks at the media briefing on COVID-19-11 March 2020. World Health Organization. https://www.who.int/director-general/speeches/detail/who-director-generals-opening-remarks-at-the-media-briefing-on-covid-19---11-march-2020

Yazıcı, G., \& Doğan, F. (2019). Interactive Imagery and Shared Mental Models in Design Learning. In N. Börekçi, D. Koçyıldırım, F. Korkut, \& D. Jones (Eds.), Proceedings of DRS Learn X Design 2019: Insider Knowledge (pp. 89-110). Middle East Technical University. https:/ / doi.org/10.21606/learnxdesign.2019.04084

Yin, R. K. (2018). Case study research and applications: Design and methods (6th edn.). Sage Publishing. 